\title{
Factors Affecting Efficient Teaching and Learning of Mathematics in Senior High Schools in Wa
}

\author{
Susuoroka Gabina ${ }^{1}$, Bernard Jagri ${ }^{2}$, Atar Alphaa Mohammed ${ }^{1}$, Abu Ahmad Anass ${ }^{1}$, \\ Al-hassan Abdul-Mumin ${ }^{1}$, Evelyn Agyei ${ }^{2}$, Cheyuo Boniface Domonaamwin ${ }^{1}$ \\ ${ }^{1}$ Mathematics and ICT Department, Nusrat Jahan Ahmadiyya College of Education, Wa, Ghana \\ ${ }^{2}$ Mathematics and ICT Department Saint, Vincent College of Education, Yendi, Ghana
}

Email address:

susuorokag@yahoo.com (S. Gabina)

\section{To cite this article:}

Susuoroka Gabina, Bernard Jagri, Atar Alphaa Mohammed, Abu Ahmad Anass, Al-hassan Abdul-Mumin, Evelyn Agyei, Cheyuo Boniface Domonaamwin. Factors Affecting Efficient Teaching and Learning of Mathematics in Senior High Schools in Wa. Teacher Education and Curriculum Studies. Vol. 6, No. 3, 2021, pp. 81-88. doi: 10.11648/j.tecs.20210603.11

Received: June 9, 2021; Accepted: June 28, 2021; Published: July 15, 2021

\begin{abstract}
A survey design was adopted in this study. Three senior high schools were randomly chosen for this study. Thirty (30) mathematics tutors and 100 learners were involved in the study. The Purpose of the study is to find out the factors that affect the actual teaching and learning of mathematics in senior high schools. To achieve this, three major questions were answered: (1) What quality teachers are teaching mathematics in our senior High schools? (2) What feelings do senior High School students display regarding the teaching and learning of mathematics? (3) What issues affect the efficient utilization of available instructional resources in the teaching of mathematics at the senior high schools? Questionnaire were used to collect data for the study. The results of the study showed that inadequate teaching and learning resources and quality tutors are some of the factors affecting the effective instruction and learning in mathematics the classroom at SHS level. From the results, the following were recommended; interactive methods of teaching mathematical concepts need to be used by mathematics teachers. In addition, stakeholders need to provide adequate teaching and learning resource to the various senior high schools.
\end{abstract}

Keywords: Factors, Affecting, Effective, Learning, Teaching and Mathematics

\section{Introduction}

Mathematics has a great influence in all aspects of human life at different levels. Mathematics is the foundation of scientific technological knowledge that is crucial in socioeconomic development of every nation. [13] suggested that a disciplined and an ordered pattern of life can only be achieved through the culture of mathematics. However, the performance of students in this important subject over the years has been very poor at all levels of education in Ghana. There is an increase attention among nations to improve the levels of mathematics achievement in schools. Besides its economic benefits, it is also contended that it would bring improved results by preparing the younger generation for the skill demands of modern workplaces, and raising the overall competence levels in the workforce. There are also other benefits associated with improving access for greater numbers of young ones to post-school education and training opportunities and laying stronger foundations for skills for a lifetime learning [24]. The attention in improving rate of attainment has led to a focus on finding the range of factors that shape achievement, as well as understanding how these factors operate to limiting or enhancing the achievement of different groups of students.

Mathematics is part of the curriculum with proper study, so several challenges have come, for example the use of nonprofessionals in the teaching of mathematics in our schools, who do not have knowledge about the subject mathematics or not mathematically oriented [24]. The indifferent behavior of students towards the teaching and learning of mathematics at large is due to the lack of use of motivational approaches of teaching by the teachers. The bad environment and inadequate number of infrastructural facilities have led to poor performances in the teaching and learning of mathematics. The total neglect in the use of the teaching and learning material (TLMs) due to lack of knowledge of teaching aides by teachers, all contribute to failure in 
effective teaching and learning of mathematics in our Senior High Schools. This research seeks to unearth the factors that affect the efficient teaching and learning of mathematics in senior high school. Therefore, the statement that the teaching and learning of mathematics in senior high schools is very crucial is of no doubt, as it is considered as a yardstick to the growth of any nation.

\subsection{Statement of the Problem}

Mathematics has been a core discipline (compulsory subject) in our secondary schools, this has made students to be studying it by force even when they are not interested, and as one cannot, further his/her studies in higher institution in any course area without at least a pass in mathematics. Students study it with grudges in mind, if it were possible for them to delete mathematics from the school curriculum, they would have done that. Some of the students implore the use of dubious means such as examination malpractices to enable them write their SSCE and pass.

Notwithstanding, the incentives the various governments and private bodies created for the promotion of studying mathematics such as the annual prize for the best senior secondary school students in the country, the scholarship package to the best mathematics degree students to study masters Overseas. Yet, students are not ready to study mathematics. The researchers began to ponder what might have caused these problems.

The researcher wishes to find out whether:

i. The cause of the problems is because of lack of trained mathematics teachers.

ii. Could it be as the result of no instructional materials in teaching mathematics?

iii. Could it be the problem of lack of textbook?

iv. Could it be as the result of a problem of methodology in teaching mathematics?

\subsection{Research Questions}

i. What quality teachers are teaching mathematics in our senior High schools?

ii. What feelings do senior High School students display regarding the teaching and learning of mathematics?

iii. What issues affect the efficient utilization of available instructional resources in the teaching of mathematics at the senior high schools?

\subsection{The Purpose of the Study}

Purpose of the study is to find out the factors that affect the actual teaching and learning of mathematics in senior high schools.

\subsection{Significance of the Study}

This study will be of numerous benefits to all in the following ways; the findings of this work will support students who are directly concerned to welcome the subject mathematics; encourage them to place more efforts in the study of mathematics since it is crucial in our daily lives.
This study will highlight the importance of mathematics, its wonders and the fun and happiness it provides, making them realize that mathematics is a stress-free subject to remove all barriers towards the study mathematics.

\subsection{Limitation of the Study}

This study will cover Wa municipal. It will focus on factors affecting effective teaching and learning of mathematics. Due to the time stipulated to cover this study, it will be a challenge to cover very school in Wa Municipal. For this reason, this study will be limited to only three public secondary Schools in the Wa Municipal. The schools are Wa senior high school, Wa senior high technical and Wa Islamic senior high school.

\section{Literature Review}

\subsection{The Caliber of Teachers Teaching Mathematics in Our Senior High Schools}

According to [7], the six main features that indicate the quality of a teacher include general ability; experience; pedagogical knowledge; subject knowledge; certification status; and teacher behaviors, practices, and beliefs with a focus on students' performance as the supported variable. The study pointed to a helpful connection between teachers and their verbal ability and students' performance in mathematics. The connection between teaching proficiency and mathematics attainment of students provided varied results; however, several studies found a positive relationship, especially at the secondary level [26]. When assessing qualities of efficient mathematics teachers on student engagement, it is important to understand what students' engagement is all about. For this reason, that, [22] recognized passionate and social commitment. They described emotional commitment as a student's satisfaction and interest in mathematics, which they deemed very important as far as motivation and attainment of students are concerned [25]. In education student commitment describes the measure of attention, curiosity, interest, optimism, and passion that students display when they are learning or being taught, which extends to the amount of motivation they have to learn and continue in their education [38]. Students engagement stems from core processes and external aids including classroom encounters, and a student's sense of selfefficacy in mathematics and helpful teacher-pupil dealings. In addition, study has proved that engaging students in the learning process buildups their attentiveness and focus, influences them to practice higher-level critical thinking skills, and supports meaningful acquiring experiences. A number of ways teachers provide support include being caring and aware of students' interest and needs, having clear anticipations, offering explicit feedback and initiating chances for conceptual thinking [2].

Bolyard, J. J. et al [7] argued that at the secondary school level, tutors who possess a degree in mathematics appears to have clear-cut impacts on student success while there is 
slight or even adverse impact on students' achievement for teachers who have any degrees other than a mathematics degree. Conversely, teachers' coursework taken precisely in the area of mathematics has positive connection on students' success; nonetheless, this appears to be inadequate, as one study discovered, that the impact fades after a certain number of courses and is manipulated by the level of courses. Overall, teachers who have degrees in mathematics have positive impacts on student achievement, and there is a positive relationship between subject-specific certifications and student achievement. Though there is a positive connection between mathematics courses and student attainment, [7], indicated that training in pedagogy is also crucial. Programs that deal on subject matter instruction with teachers, having a narrow mathematical knowledge of the content has negative effects on pedagogical content knowledge and instructional quality and student progress which persist across their entire teaching careers [5]. The Mathematics Teacher Transformation Institute appraised usefulness of teaching by measuring student engagement in mathematics cited in [15] uncovered that teachers who employed a high level of learner-centered, inquiry-based pedagogy were more efficient algebra and geometry teachers than those who did not. Conversely, they also found out that there was no connection among the growth in content knowledge and a teacher's use of learner-centered imparting. According to [34], eighth grade students in the United States and Korea, whereas teachers' educational backgrounds are not linked with high-quality mathematics teaching in Korea, the contrary is right in the United States where teachers who majored in both education and mathematics are 2 to 4 times more likely to be categorized into the high quality group than tutors who did not major in education or mathematics and used other channel into the teaching profession. Expert development prospects were a distinguishing factor for teachers who had high-quality instruction but low selfefficacy and for teachers who had low-quality instruction but high self-efficacy from those that were low in both quality instruction and self-efficacy. In the United States, there is a positive connection between mathematical instruction, teacher self-efficacy, and learner attainment in mathematics; however, in Korea, there is no significant connection amongst the three. The discrepancy regarding this, while [7] study focused on tutor coursework, [18] aimed on practices of mathematics tutors unconcerned courses including superior placement, respects, and consistent classes. While he did not evaluate the effectiveness of teacher strategies on student outcomes, [18] did find significant differences in expectations. Mathematics teachers who taught a combination of Advanced Placement, accolades and consistent mathematics classes showed they trust students in Advanced Placement classes should be assigned homework on a more regular basis and the lessons should have more clear structure than in regular mathematics courses. In their honors mathematics courses, teachers felt it was better to go into more depth on less topics; but, in the AP courses, teachers did not hold this opinion and may have sensed they were not allowed to ignore any topics. In their AP classes, tutors showed placing appreciably greater emphasis on comprehending mathematical knowledges, stressing mathematical practices, understanding real-life usage, growing interest in mathematics and preparing for further studies in mathematics than in their regular math courses.

\subsection{The Feeling of Students to Learning of Mathematics in Senior High Schools}

Numerous reasons have been identified in the literature to be the underlying cause of underachievement among high school students in mathematics [31]. A major factor deliberated in most narrative to have great influence on learners' success in mathematics is learners' attitude about the subject [19]. [33] reported in a study of secondary school students in Pakistan that students' success in mathematics is dependent on their attitude towards the subject. Students' thinking and postures were found to have the potential to either assist or hinder learning. Several studies have shown a strong and important connection between students' mathematics feelings and mathematics success [30, 32]. [27] also contends that the success of students in a subject is decided by their attitudes towards the subject rather that their inability to study. He conceded that the role attitude plays in limiting the attainment of any success is remarkable. This consequently suggests that student $\mathrm{s}$ should develop favorable attitude towards mathematics is success is to be attained.

Studies have shown that the formation of a particular attitude is an experience. People create relationships through their own life experiences. Social psychology explains how attitudes are formed using three main theories of learning: classical conditioning and observational learning. According to Ivan Pavlov, classical conditioning is a process of behavior change in which the re-association of a conditioned stimulus with an unconditional stimulus leads to the development of a conditioned response [28, 21]. Classical conditioning involves a neutral stimulus that naturally triggers a response. Children, for example, can be fans of clubs, fathers of homes. They grow up believing that some cars are the best, and they develop a passion for the club. So, we create relationships based on how we are conditioned to be, which is what our experience gives us. B. F. Skinner's theory of operant conditioning is a form of learning in which the response takes place in anticipation of a stimulus. In conditioning, reinforcement increases the likelihood that the behavior will be repeated [28]. Behaviors that are followed by positive effects are amplified and are more often recalled than those that lead to negative consequences [23]. Conditioning follows when using positive reinforcement and punishment [20]. For example, if a child's mother smiles at her every time she has something for her, she begins to realize that it's okay to be helpful, and is likely to do this behavior again. Of course, if the mother yells at the baby for what he did, or with one part of the device, then the child will grow up at a disadvantage in relation to smokers, as well as those who smoke. This is due to the negative consequences of his actions. 


\subsection{The Factors Affecting Effective Use of Available Teaching and Learning Materials in the Mathematics Classroom}

Instructional materials and the learning environment are major elements in teaching and learning of mathematics. The successful use of teaching learning materials by mathematics teachers have a great impact in stimulating and sustaining students' interest in mathematics. Their effective use helps in reducing the level of obstruction in teaching a topic i.e. they concretize the abstract nature of mathematics. They also stimulate students' imagination and help them retain the concepts learnt. Teaching aids should be provided for mathematics teachers. The teachers, in turn, should utilized these aids, involving the students in their use. The teacher should also improvise some of the teaching aids that he cannot acquire by using local resources. The impact of a teacher's attitude in the mathematics classroom on his/her learners cannot be over-emphasized. According to [40], "Teacher attitude is one of the most powerful forces affecting students' progress". Teachers with good attitude will like to use instructional material during his/her teaching [4]. The key instrument in the teaching and learning of mathematics is the textbook because it is being used as a guide in the teaching of the subject. It is therefore important that mathematics textbooks be of good yardstick that can improve the teaching and learning of mathematics. However, mathematics lessons need to be enriched with teaching aids like concrete materials, pictures, demonstrations etc. to help students' comprehension. Regrettably, such are usually not available due to teacher's convenience or lack of interest to provide such environment. these further complicate issues for students who have always complained that mathematics is too abstract. In addition, time is not often available for the use of teaching and learning materials in the mathematics classroom [37].

One of the factors, which causes poor performances of students in mathematics in secondary schools and discourages students from studying mathematics, is poor teaching [3]. The role of the teacher in the company's education should not be left unattended. According to [36]. Teachers are the focal points of the education system, and their number, quality, and interaction will determine the success of the education system.

\section{Methodology}

The design and methodology used in the execution of this research work are being discussed under the following headings: Research Design of the study, Area of the Study, Population of the Study, Sample, Sampling techniques, Instrument for data Collection, Validation of the instrument, Reliability of the instrument, method of data collection, and method of data analysis.

\subsection{Design}

The design for this study is the survey research design. It involves the use of questionnaire in collection of information on mathematics teachers of Senior High Schools and students of mathematics department in those schools. All the questions are geared towards the factors and causes responsible for the problems that mathematics teachers are encountering in the tutoring of mathematics in our senior high schools. The reason for choosing this type of design (survey) is that it is less expensive and saves times.

\subsection{The Study Area}

Three Senior High Schools in the Wa Municipality were selected for the study. The three senior high schools are Wa senior high school, Wa senior high technical and Wa Islamic senior high school. The area was chosen because of proximity and convenience for effective research work. The schools consisted of male and female teachers and coeducational schools in the area.

\subsection{Population of the Study}

A research population is generally a large group of individuals or objects to which researchers sometimes generalize their findings [35]. [8] define a target population as a group of elements or cases that match to specific criteria and to whom a researcher intends to generalize a study. The population of this study consisted of all math teachers and students from all high schools in the Upper West Region.

\subsubsection{Sample and Sampling Techniques}

A sample is any part of a population regardless of whether it is representative or not [14]. Sampling is the process of selecting a portion of the population to represent the entire population [1]. Sampling technique for the study was simple random sampling. Simple random sampling is a process of selecting a sample from a population where every member of the population has an equal chance of being included in the sample [29]. The sample size that was used in the study was one hundred (100) students and thirty (30) mathematics teachers. According to [9] "a sample size of 30 is held by many to be the minimum number of cases if researchers plan to use some form of statistical analysis on their data" ( $p$. 101). Hence, the sample size is highly representative population and could be used to draw valid conclusions [11]. Table below shows the summary of the participants in this study.

Table 1. Summary of Participants in the Study. The schools, Number of teachers and students.

\begin{tabular}{lll}
\hline School & Number of teachers & Number of students \\
\hline Wa SHS & 10 & 35 \\
Wa SHST & 10 & 35 \\
Wa Islamic & 10 & 30 \\
Total & 30 & 100 \\
\hline
\end{tabular}

\subsubsection{Source of Data Collection}

The data for this study were collected via primary and secondary source. The secondary source of data was collected from journals, magazines and related Study. In addition, the primary was collected from the questionnaire 
distributed to the respondents

\subsubsection{Research Instrument}

Wildinson, D. et al [39] define research instruments as simply devices for collection of data significant to a research task. These include tests, questionnaire and interviews. They however argue that, there is no single research instrument that is accepted as standard. Therefore, no single research instrument is more appropriate than the other is. The main research instrument is a self-constructed questionnaire based on the problem of the study. The questionnaires were used to extract information from the respondents on the problems influencing efficient teaching and learning of mathematics in senior secondary school, in Wa Municipal, Upper WestGhana. The questionnaire was designed for both teachers and students. The questionnaire on the subject matter contained agree, strongly agree, disagree and strongly disagree responses item.

\subsubsection{Questionnaire}

According to [38], a questionnaire has several advantages, which include facilitating data gathering, easy to test data for validity and reliability, less time consuming than interview and observation. It also preserves the anonymity and confidentiality of the respondents' reactions and answers. Description of [16] and simple written questions that are the answer to the marker/circled in the corresponding field. These are the most effective ways to collect facts. The questionnaire can also be used as a device to gather information about people's opinions, often asking respondents to determine how much they agree or disagree with the statement that the Likert scale is one of the most commonly used methods in the bowl set of social science questionnaires to date. A questionnaire was used for this study. The questionnaire was designed based on the objectives of the study. The questionnaire was on closedended questions. The closed-ended questions were used to gather specific responses from the respondents. See Appendix A. The researcher used this data collection approach because the responses were gathered in standardized ways and so they are more objective and certain. Closed-ended questions according to [10] are quick to compile and straight forward to code and do not discriminate unduly based on how articulate the respondents are. Again, the use of questionnaires speeds up the collection of information, potentially information can be collected from a large portion of a group and it is easy to analyze [6]. Data entry and tabulation can be easily done with many computer software packages like Statistical Package for Social Science (SPSS) version 20 and Microsoft Excel 2010.

\subsubsection{Scoring the Questionnaires (Likert Scale Type Items)}

The Likert scale with four options Agree, Strongly Agree, Disagree and Strongly Disagree was scored 3, 4, 1 and 2 respectively. This was used to determine the factors that influence effective teaching and learning of mathematics in our senior high schools in Ghana. The Likert scale four options were re-coded into two scale option levels namely:
Agreement and Disagreement levels. Agree and Strongly Agree were re-coded into the agreement level while the Disagree and Strongly Disagree categories were re-coded into Disagreement level. The aggregate scores were obtained by computing students' responses to the variables to determine their agreement level to each item of the variable by using the frequency count tool in Statistical Package for Social Sciences (SPSS).

\subsubsection{Validation of Instrument}

The research instrument was submitted to an experience project supervisor for correction. Pilot study was conducted, using ten students and 5 teachers from one of the selected schools. The result of the pilot study was analyzed using SPSS. After taking permission from the school head, the instrument was administered to the teachers and students and was retrieved immediately after completion.

\subsubsection{Data Collection Procedure}

The researcher started by obtaining permission from the Heads of the selected schools to use the students of the schools. The researcher together with some teachers then administered the questionnaire to the selected teachers and students.

\subsubsection{Data Analysis}

The responses of participants will be analyzed with the help of SPSS version 20. Data analysis using the statistics will display the frequency, percentage, deviation and mean. The statistics also reflect the factors the respondents think are influencing effective teaching and learning of mathematics and the quality of mathematics teachers in the senior high schools.

\subsubsection{Ethical Consideration}

In research studies, researchers are expected to cautiously and ethically analyze any ethical concerns [17]. The researcher adhered to ethical guidelines governing human subjects in research. The names of teachers and students were not released in the research. Secondly, the features of the questionnaires such as ease of completion, sensitivity of the questionnaire were all considered. The names of participants were not needed on the questionnaire and they were informed about subject anonymity and confidentiality. The researcher conducted the research without disturbing the learning atmosphere of the schools.

\section{Results and Discussion}

\subsection{The Qualities of Teachers Teaching Mathematics in Senior High Schools}

Academic qualification was an essential quality of the mathematics teacher the researcher considered in determining whether teachers teaching mathematics in the Senior High Schools were trained and competent. To achieve this, the responses from the participants were analyzed and results displayed in table 1 as shown below. 
Table 2. Indicating qualification of mathematics teachers in schools sampled for the study.

\begin{tabular}{llll}
\hline s/n & Qualification & No. of teachers & Percentage \\
\hline 1 & P.HD & 0 & 0 \\
2 & M.PHIL/M.ED/M.SC/M.A & 10 & 33.3 \\
3 & B.SC/B.ED/B.A & 18 & 60 \\
4 & DIPLOMA/HND & 2 & 6.7 \\
5 & CERT. A & 0 & 0 \\
\hline
\end{tabular}

Table 2 shows that majority of mathematics teachers 18 $(60 \%)$ are holders of Bachelor degree in education, a small number $2(6.7 \%)$ have diploma qualification. Also, quite a number $10(33.3 \%)$ have masters. The findings show that generally an overwhelming number of mathematics teachers have undergone training in education. Therefore, they have been trained in special methods of teaching mathematics hence they are well equipped to teach the subject.

\subsection{The Attitudes of Students Towards Teaching and Learning of Mathematics in Senior High Schools}

This research question was formulated to search for some attitudes of students towards learning mathematics at the senior high school level. To achieve this a nine (9) Likert scale type items (see Appendix A for questionnaire) were administered to students to rate the level to which they agree or disagree to the attitudes they have towards learning mathematics. To explain this the responses/results were categorized into agreement levels, which include strongly agree and agree and disagreement levels comprising strongly disagree and disagree including their descriptive statistics. The results are display in Table 3 below.

Table 3. The attitudes of students towards teaching and learning of mathematics in senior high schools.

\begin{tabular}{|c|c|c|c|c|c|}
\hline Statement on attitude towards mathematics & Agreement N (\%) & Disagreement $\mathbf{N}(\%)$ & Mean & SD & Total \\
\hline I hate mathematics & $90(90)$ & $10(10)$ & 3.35 & 0.744 & 100 \\
\hline I just cannot do mathematics & $96(96)$ & $4(4)$ & 3.40 & 0.569 & 100 \\
\hline I will never be good at it, so what is the point in trying & $94(94)$ & $6(6)$ & 3.29 & 0.640 & 100 \\
\hline I have a feeling of dislike for mathematics & $98(98)$ & $2(2)$ & 3.56 & 0.574 & 100 \\
\hline I am always confused during mathematics lessons & $81(81)$ & $19(19)$ & 3.14 & 0.472 & 100 \\
\hline I usually enjoy studying mathematics in school & $3(3)$ & $97(97)$ & 1.55 & 0.592 & 100 \\
\hline I like to solve problems in mathematics & $2(2)$ & $98(98)$ & 1.42 & 0.535 & 100 \\
\hline I really like mathematics & $15(15)$ & $85(85)$ & 1.85 & 0.359 & 100 \\
\hline
\end{tabular}

The results in Table 3 show that majority of the students did indicate a favorable agreement to the attitudes of students towards learning of mathematics in senior high schools. Most participants show disagreement on the following statements: I usually enjoy studying mathematics in school 97 (97\%), I like to solve problems in mathematics $98(98 \%)$ and I really like mathematics $85(85 \%)$ but agreed to the following: I am always confused during mathematics lessons 81 (81\%), I have a feeling of dislike for mathematics 98 (98\%), I will never be good at it, so what is the point in trying 94 (94\%), I just cannot do mathematics 96 (96\%) and I hate mathematics $90(90 \%)$. This suggest that the students generally agreed to their attitudes of towards learning of mathematics in senior high schools. The students mean ratings of the statements indicating the factors affecting effective teaching and learning of mathematics were also determined. Table 3 shows that the mean agreement was higher on the negative items than positive ones. For example, the means of students hating mathematics and cannot do mathematics are 3.35 and 3.40 respectively. This indicate that all the participants reasoned in line with agreement with scale points 3 and 4 . The respondents agreeing with these items means they are some of the attitudes of students towards learning of mathematics in senior high schools. The standard deviation gives an idea of how a person responds to a resolution or differs from the average response. It also gives an idea of the distribution of ratings around the average value. The smaller the standard deviation, the more the distance between the lowest and highest score will decrease.

\subsection{The Factors Affecting Effective Utilization of Available Teaching and Learning Materials in the Mathematics Classroom}

Research question three (3) was formulated to search for some attitudes of students towards learning mathematics at the senior high school level. To achieve this a four (4) Openended items (see Appendix A for questionnaire) were constructed to explore the factors that militate against effective utilization of available instructional materials in the teaching of mathematics. To explain this the responses/results were categorized into agreement levels, which include strongly agree and agree and disagreement levels comprising strongly disagree and disagree including their descriptive statistics. The results were display in Table 4 below.

Table 4. The factors affecting effective utilization of available teaching and learning materials in the mathematics classroom.

\begin{tabular}{|c|c|c|c|c|c|}
\hline Statement on factors against effective use of TLMs & Agreement N (\%) & Disagreement N (\%) & Mean & SD & Total \\
\hline Inadequate instructional materials affects the teaching of mathematics & $28(93.3)$ & $2(6.7)$ & 3.3667 & 0.6150 & 30 \\
\hline Inappropriate teaching methodology affects the teaching of mathematics & $30(100)$ & $0(0)$ & 3.8000 & 0.4068 & 30 \\
\hline Teachers' communication skills affects the teaching of mathematics & $28(93.3)$ & $2(6.7)$ & 3.7000 & 0.7022 & 30 \\
\hline Inadequate preparation affects the teaching of mathematics & $30(100)$ & $0(0)$ & 3.3667 & 0.4901 & 30 \\
\hline
\end{tabular}


Table 4 shows that the participants indicated agreement to statements like: Inadequate instructional materials affects the teaching of mathematics $28(93.3 \%)$, Inappropriate teaching methodology affects the teaching of mathematics 30 (100\%), Teachers' communication skills affects the teaching of mathematics $28(93.3 \%)$ and Inadequate preparation affects the teaching of mathematics $30(100 \%)$.

From Table 4, the mean perceived factors militating against effective utilization of available instructional material in the teaching of mathematics are between 3 and 4 indicating majority of respondents associate themselves with the factors which were coded as 3 and 4 . The standard deviations were all less than 1 indicating their decision to the factors militating against effective utilization of available instructional materials in the teaching of mathematics. It was indicated the highest factors militating against effective utilization of available instructional materials in the teaching of mathematics include the following: Inadequate instructional materials, inappropriate teaching methodology, Teachers' communication skills and inadequate preparation.

\section{Findings}

Results from the questionnaire showed that almost all the respondents agreed on the idea that the quality of the mathematics teacher has a great effect on the teaching and learning of mathematics.

Almost all of the respondents agreed on the notion that inadequate instructional materials, inappropriate teaching approach, teachers' communication skills and inadequate preparation are factors influencing effective teaching and learning of mathematics. In addition to this, among these instructional factors, instructional strategies and methods is the most influential factor.

\section{Conclusion and Recommendation}

\subsection{Conclusion}

The finding of this study have provided the basis for the research to draw the conclusion that certain factors such as the qualification of mathematics teachers in schools, the attitudes of students towards learning of mathematics in senior high schools, inadequate instructional materials, inappropriate teaching methodology, teachers' communication skills and inadequate preparation are some of the factors that influence effective teaching and learning of mathematics. Conclusively, all stakeholders in mathematics education are called upon to intensify efforts towards the production and utilization of teacher made instructional materials for effective teaching and learning of mathematics in senior high schools in Ghana.

\subsection{Recommendations}

The results of this study provide the following recommendations:
1) Encourage mathematics teachers to participate in seminars, master classes and conferences to improve their knowledge and skills in the production and use of didactic materials;

2) Teaching and training of student teachers requires revision in order to emphasize the knowledge and skills associated with the production and use of educational materials.

3) Sufficient funds should be available for the purchase of tools and materials necessary for the production of educational teaching materials.

4) All secondary schools in Ghana should have organized and functional workshops for improvising teaching materials.

5) Subjects (public authorities at various levels of government) should ensure that mathematics teachers are motivated to perform their professional duties, for example, to improvise educational materials.

\section{References}

[1] Alhassan, S. (2006). Modern approaches to research in educational administration. Kumasi: Playless publication Ltd.

[2] American Heritage Dictionary. (2000). The American Heritage Dictionary of Indo-European Roots. (C. Watkins, Ed.) Houghton Mifflin Harcourt: Trade and Reference Publishers.

[3] Amoo, S. A. (2000). Secondary school mathematics teachers' characteristics and their teaching effectiveness. Journal of Primary Science, 2 (1), 29-35.

[4] Banks, J. A. (2004). Teaching for Social Justice, Delivery, and Citizenship in a Global World. The Educational Forum, 68 (4), 34-56.

[5] Baumert, J. (2010). Teachers' mathematical knowledge, cognitive activation in the classroom, and student progress. American Educational Research Journal, 47 (1), 133-180.

[6] Baxter, P., \& Jack, S. (2008). Qualitative Case Study Methodology: Study Design and Implementation for Novice Researchers. The Qualitative Report, 13 (4), 544-559.

[7] Bolyard, J. J., \& Moyer-Packenham, P. S. (2008). A review of the literature on mathematics and science teacher quality. Peabody Journal of Education, 83 (4), 509-535.

[8] Cohen, C. (2004). Research methods in education (Vol. IV). London: Routledge Falmer.

[9] Cohen, L., Manion, L., \& Morison, K. (2008). Research Methods in Education (V ed.). USA: Routhledge Falmer.

[10] Cohen, L., Manion, L., \& Morrison, K. (2013). Research Methods in Education (VI ed.).

[11] Cohen, L., Manion, L., \& Morrison, K. (2008). Research methods in education (VI ed.). S. A: Routhledge.

[12] Encyclopedia Britannca. (1994). Fair Division: From CakeCutting to Disput Resolution. Cambridge: University Press Amazon. com. 
[13] Eraikhuemen, I. (2003). Mathematcs as an Essential tool for Universal Basic Education. The Journal of the Mathematical Association of Nigeria, 28 (1), 1-6.

[14] George, D. D., \& Mensah, D. D. (2012). A Practical Guide to Action and Case Study Reserch. Amakom-Kumasi: Payless Publication Limited.

[15] Gningue, S. M. (2013). Developing effective mathematics teaching: Assessing content and pedagogical knowledge, student-centered teaching, and students' engagement. The Mathematics Enthusiast, 10 (3), 621-646.

[16] Hannan, P. J. (2007). The Influence of Socio demographic Factors on Patterns of Fruit and Vegetable Consumption in Canadian Adolescent. Journal of the American Dietetic Association., 107 (9), 1511-1518.

[17] Jack, R. F. (2003). How to Design and Evaluate Research in Education. Boston: McGraw Hill Publishers.

[18] Judson, E. (2017). How science and math teachers address different course levels: Advanced placement (AP), honors, and regular. The High School Journal, 100 (4), 226-249.

[19] Khaliq, A., \& Rodrigues, S. (2012). Secondary school students' attitudes towards mathematics in Quetta, Pakistan. International Researchers, 1 (2), 15-28.

[20] Linero, J. V., \& Hinojosa, M. (2012). Theories of Learning and Student Development. National forum of teacher education journal, 22 (3), 23-45.

[21] Lineros, J. V., \& Hinojosa, M. (2012). Theories of learning and student development.. National Forum of Teachers Education Journal., 1-5.

[22] Martin, D. P., \& Rimm-Kaufman, S. E. (2015). Do student self-efficacy and teacher-student interaction quality contribute to emotional and social engagement in fifth grade math? Journal of School Psychology, 53 (5), 359-373.

[23] Moris, C. G., \& Maisto, H. (2001). Understanding psychology (5th ed.). Boston: Pearson.

[24] Mereku K. D. (2001). An investigation into factors that influence teachers content coverage in primary Mathematics. African Journal of Education Studies in Mathematics and Science, 1.

[25] Moseri, P. O., Onwuka, P. O., \& Iweka, S. (2010). A tool for improving the teaching and learning of mathematics for attainment of seven point agenda. Proceeding of Annual National Conference of Mathematics Association.. Ilorin: Unilorin Press.

[26] Moyer, P. S. (2008). Are we having fun yet? How teachers use manipulatives to teach mathematics. Educational Studies in Mathematics, 175 (197), 47.
[27] Moyer-Packenham, P. S., Bolyard, J. J., Kitsantas, A., \& Oh, H. (2008). The assessment of mathematics and science teacher quality. Peabody Journal of Education, 83 (4), 562-591.

[28] Mwamwendwa, T. S. (1995). Educational psychology: An African perspective. London: Heinemann Butterworth Ltd.

[29] Ntim, S. K. (2010). Theory and Method of Education: Psychological Perspectives on Learning. Takoradi: St Francis Press Ltd.

[30] Opoku, J. Y. (2005). A short guide to research writing in the social science and education.. Accra: Ghana Universities Press.

[31] Randhawa, B. S., \& Beamer, J. E. (1992). Role of mathematics self-efficacy in the structural model of mathematics achievment. Journal of Educational Psychology, 85 (1), 41-48

[32] Saritas, T., \& Akdemir, O. (2009). Identifying Factors Affecting the Mathematics Achievement of Student for Better Instructural Design. International Journal of Instructional Technology and Distance Learning Education, 49 (1), 15-31.

[33] Schenkel, B. (2009). The impact of an attitude toward matheamtics on mathematics performance. Mariette College: Unpublished MA thesis.

[34] Shah, U. (2008). Students' attitude towards mathematics. Pakistan Economic and Social Review, 46 (1), 75-83.

[35] Son, J. W. (2015). Quality instruction, teachers' self-efficacy, and student math achievement in Korea and United States. Psycology of Mathematics \& Education of North America, (pp. 1142-1145).

[36] Trochim, W. K. (2006). Research Methods Knowledge Base. Retrieved November 20, 2014, from http://www.socialresearchmethods.net/kb/order.php

[37] Ukeje, E. (1974). Teacher Quality Factors as Determinant of Students' Achievment in Mathematics. Journal of Education, 2 (4), 36-41.

[38] Umar, A. (1995). Effects of teachers' qualifications on performance in further matheamtics among secondary school students. Mathematics theory and modeling, 1 (3), 2225-6522.

[39] Wildinson, D., \& Birmingham, P. (2003). Using Research Instruments: A Guide for Researchers. Routledge Study Guide.

[40] Wiseman, K. (2004). Evironmental assessment and planning in South Africa: the SEA connection. In R. P. M., \& C. R., Perspectives on Strategic Environmental Assessment (pp. 155166). Florida: Lewis Publishers, Boca Raton. 